\title{
Effects of context exposure during conditioning on conditioned taste aversions
}

\author{
CARLA BILLS, SHAWN SMITH, NAOMI MYERS, and TODD R. SCHACHTMAN \\ University of Missouri, Columbia, Missouri
}

\begin{abstract}
Rats were used in a conditioned taste aversion procedure in order to examine the effects of context exposure duration during the conditioning sessions on conditioned responding. One flavor was paired with lithium chloride during a long session in one context, whereas another flavor was conditioned during a short session in another context. Testing occurred in the home cage. The results showed that conditioning during short sessions produced strong conditioned taste aversions. Conditioning during long sessions produced strong conditioned taste aversions when the conditioned-stimulus-unconditionedstimulus (CS-US) pairing occurred at the end of the lengthy session. Other results showed that context-US associations were formed during the short duration sessions and that these associations supported conditioned responding to the CS trained in that context. The results are discussed with respect to the different influences that contextual cues can exert on conditioned responding.
\end{abstract}

The influence of contextual cues during classical conditioning has received a great deal of attention(e.g., Balsam $\&$ Tomie, 1985). It is now clear that the occurrence of conditioned responding to a conditioned stimulus (CS) is influenced by learning about contextual cues (usually defined as the static apparatus cues present during the experimental procedures conducted with the target CS). Contextual cues serve many roles during conditioning, including attenuation of learning about the CS (e.g., Balsam \& Schwartz, 1981; Weaver \& Gordon, 1988), enhancement of processing of the CS (Gordon \& Mowrer, 1980), and enhancement of performance to the CS (e.g., Bouton \& Bolles, 1985; Marlin, 1982; Miller \& Schachtman, 1985b; Rescorla, Durlach, \& Grau, 1985).

One common treatment involving contextual cues during conditioning has been to manipulate the amount of exposure subjects receive to the contextual cues-for example, by manipulating the duration of the intertrial interval (ITI). This context exposure is believed to influence the strength of the association between the context and the unconditioned stimulus (US) in such a way that longer ITIs (greater context exposure during the conditioning sessions) produce a weaker context-US association (Gibbon \& Balsam, 1981; Jenkins, Barnes, \& Barrera, 1981; Kasprow, Schachtman, \& Miller, 1987). This presumably occurs because the long ITIs allow the context to extinguish during the intervals between trials; the resulting weaker context-US associations are viewed as promoting stronger conditioned responding to the $\mathrm{CS}$ trained in that context.

Support for this project was provided by NIMH Grant RO1 MH5903901. We thank J. Calton, J. Hart, M. McEwen, and B. Butchart for assistance in conducting these experiments and Bob Batsell and Steve Reilly for reading an earlier version of this article. Correspondence concerning this article should be addressed to T. R. Schachtman, Department of Psychology, 210 McAlester Hall, University of Missouri, Columbia, MO 65211 (e-mail: schachtmant@missouri.edu).
Comparator theories of the role of context in classical conditioning claim that-assuming that the CS is tested in a neutral context so that the associative strength of the context is not able to summate with that of the CS during testing - the weaker the context-US association, the stronger the conditioned response (CR) to the $\mathrm{CS}$ that was conditioned in that context (Gibbon \& Balsam, 1981; Miller \& Schachtman, 1985a). Comparator theories (Gibbon \& Balsam, 1981; Miller \& Matzel, 1988) make this prediction by claiming that the strength of the CR to a CS is large to the extent that the CS-US association is strong and the contextUS association (referring to the context in which CS conditioning occurred) is weak. The models claim that, at the time at which a CS is tested for conditioned responding, the subject compares the associative strength of the CS with that of the context and that, as a result of this comparator process, the extent to which the associative strength of the former exceeds that of the latter will determine the magnitude of the $\mathrm{CR}$.

Although a number of recent studies have contributed to such findings, very little work on context exposure effects, such as those with variations in ITI, has evaluated them with a conditioned taste aversion (CTA) procedure. On the one hand, this paucity of such data can be expected since some of the temporal parameters (e.g., US onset and offset, interstimulus interval) are difficult to specify precisely when this procedure is used. Moreover, the manipulation of the interval between trials with a CTA procedure is not comparable to other procedures, since the subjects rarely receive more than one trial per session (but see Domjan, 1980). The interval between the CS and the US can also be seen as less critical, since conditioning with CTA, of course, can be obtained despite very long intervals between these stimuli. Domjan (1980) used a CTA procedure with conditioning trials occurring in the home cage and found that a 35-min ITI produced a poorer CR than did a 3-day ITI. 
Domjan (1980) concluded that the short ITI condition caused the aftereffects of the first conditioning trial to interfere with conditioning on the second conditioning trial (see also Best, 1982). Since Domjan's (1980) treatments occurred in the home cage, the issue regarding the manipulation of discrete contextual cues remains. Hence, despite the limitations of using a CTA procedure, the importance of recognizing the role of duration of context exposure on conditioned taste aversions has not been determined. CTA has often been evaluated with respect to its having a "unique status" as a learning process, with its own laws and principles, because of its rapid acquisition and its ability to withstand long temporal intervals between the $\mathrm{CS}$ and the US (cf. Domjan, 1983). In the present experiments, we sought to examine the effects of context duration, using a CTA procedure.

\section{EXPERIMENT 1}

Following acclimation to the contexts, all the subjects received two pairings of one flavored solution with lithium chloride $(\mathrm{LiCl})$ during 15-min sessions in one distinctive context and two pairings of a second flavor with $\mathrm{LiCl}$ during 60-min sessions in another distinctive context. Each CS was then tested during CS-alone extinction exposures in the home cage. More than one conditioning trial was administered in order to facilitate adequate discrimination of the contexts and discrimination of the session lengths for the two flavors.

\section{Method}

Subjects. Nine female and 7 male Sprague-Dawley-derived rats bred in the University of Missouri colony served as subjects. At the start of the study, the ranges of their body weights were 348-549 and $248-325 \mathrm{~g}$ for the male and the female rats, respectively. Each rat was individually housed in a hanging, stainless steel, wire-mesh cage that measured $24 \times 17.7 \times 18.2 \mathrm{~cm}(1 \times \mathrm{w} \times \mathrm{h})$, with ad-lib access to lab chow. The subjects were handled several times prior to the start of the experiment. The rats were also water deprived prior to the start of the experiment, using a graded water deprivation schedule that culminated in $10 \mathrm{~min}$ of water access each day. Water access occurred in the home cage after each day's treatments, approximately $23.5 \mathrm{~h}$ prior to the experimental manipulations of the next day. The room housing the animals was on a 16:8-h light:dark cycle, and treatments occurred during the middle of the light portion of the cycle.

Apparatus, solutions, and drugs. The experiment used two distinctly different experimental contexts. Context 1 was provided by 16 copies of a small (measuring $28.8 \times 17.9 \times 12.2 \mathrm{~cm}[1 \times \mathrm{w} \times \mathrm{h}]$ ), off-white, nearly opaque box made of polycarbonate plastic, with a lid constructed of parallel stainless steel rods that were spaced $0.8 \mathrm{~cm}$ apart. The room was brightly illuminated, relatively odorless, and quiet. Context 2 was provided by 16 clear, plastic boxes. These chambers, large breeding cages, had sloping ceilings constructed of parallel stainless steel rods that were spaced $0.9 \mathrm{~cm}$ apart. They measured $36.1 \times 31.3 \times 17 \mathrm{~cm}(1 \times \mathrm{w} \times \mathrm{h})$ at the greatest height of the chambers. There was approximately $1.0 \mathrm{~cm}$ of aspen wood shavings lining the floor of these chambers. These chambers were located in a dimly illuminated room with the odor of methyl (Vicks Vaporub) and a soft white noise present. Hence, the two contexts differed in brightness, shavings, odor, background noise, and type of plastic construction material, and rats have been shown to be able to discriminate these two contexts (Chelonis, Calton, Hart, \& Schachtman, 1999).
Flavored solutions were presented in a plastic drinking tube (a modified, inverted $50-\mathrm{ml}$ syringe with a metal lick tube attached). A $3 \%(\mathrm{v} / \mathrm{v})$ vinegar (Heinz apple cider vinegar) solution was used, as well as a $1.5 \%(w / v)$ coffee solution (Sanka, General Foods, White Plains, NY). $\mathrm{LiCl}$ was administered as an intraperitoneal (i.p.) injection of $0.15 \mathrm{M} \mathrm{LiCl}$ (Sigma Co., St. Louis, MO) at $0.5 \%$ body weight, using a 25 -ga, 1.59 -cm hypodermic needle.

Procedure. The rats were given a single 20-min exposure to each of the two contexts, with water available in drinking tubes on Day 1. Half of the rats were placed in Context 1 for 20 min and then were placed in Context 2 for $20 \mathrm{~min}$. The remaining rats received the two contexts in the reverse order.

During the conditioning phase (Days 2-9), all the rats received two conditioning trials with one flavor during a long session and two conditioning trials with a second flavor during a short session. Hence, the effect of session duration on CTA was a within-subjects factor. Only one conditioning trial occurred per session, and each subject received only one session per day. On Day 2, half of the rats received a 15-min session (short condition). Each of these rats was placed in the context for $5 \mathrm{~min}$, then received a 5 -min presentation of the flavored solution (either the vinegar solution [Vin] or the coffee solution [Coff]), followed by an injection of $\mathrm{LiCl}$, and then stayed in the context for what remained of the 15-min session (approximately $5 \mathrm{~min}$ ) before being taken to the home cage. On Day 3 , the rats remained in the home cages. On Day 4, these rats received a 60-min session (long condition) containing the pairing of the flavored solution (either Vin or Coff) with the $\mathrm{LiCl}$ injection, as described below. The other half of the rats received the long condition on Day 2 and the short condition on Day 4.

There were two subconditions of the long condition. These subgroups constituted what was essentially a between-groups counterbalancing manipulation. During their long session, half of the subjects (the long-begin condition, $n=8$ ) were placed in the context for $5 \mathrm{~min}$; they then received the flavored solution for $5 \mathrm{~min}$, followed by the injection of $\mathrm{LiCl}$, and then remained in the context for the time that was left in the 60-min session (approximately $50 \mathrm{~min}$ ) before being removed and taken to their home cages. The other subjects (the long-end condition, $n=8$ ), during their long session, were placed in the context for $50 \mathrm{~min}$; they then received a 5-min presentation of the flavored solution, followed by the $\mathrm{LiCl}$ injection, and then remained in the context for the remainder of the 60-min session (approximately $5 \mathrm{~min}$ ) before being taken to their home cages. This between-groups factor was counterbalanced for sex and body weight to the extent possible.

Half of the subjects consumed Vin during the short condition, whereas the remaining subjects drank Coff during this session. Of course, for a given rat, a particular flavor was always conditioned in a particular context (e.g., Coff in Context 1) of a particular session duration (e.g., long). Day 6 was identical to Day 2. Day 8 was identical to Day 4. On Days 3 (as was mentioned), 5, 7, and 9, the rats remained in the home cages to recover from the $\mathrm{LiCl}$ injections.

Testing occurred on Days 10-21 in the home cages. Given the strong aversions produced by CTA, the use of two conditioning trials meant that during testing, many extinction trials were necessary to detect differences between the conditions. There were six test exposures for each flavor. On each of Days 10, 12, 14, 16, 18, and 20, half of the subjects received a Coff extinction trial for $5 \mathrm{~min}$ in the home cages. The remaining rats received Vin on these days. The subjects received the alternative flavor during the other test sessions (Days 11, 13, 15, 17, 19, and 21). Flavored solutions given during all of the experimental treatments were recorded by weighing the drinking tubes before and after treatment.

\section{Results and Discussion}

Three rats were lost, 1 from long-end condition and 2 from the long-begin condition, due to illness or procedural error. The rats consumed comparable amounts of Vin and 
Coff during conditioning, and there were no differences in consumption in the two chamber types, as was revealed by analyses of variance [ANOVAs; $F_{\mathrm{s}}(1,10)<2.40, p \mathrm{~s}>.15$ ].

A within-subjects ANOVA conducted on the conditioning data showed that the subjects in the short and the long conditions consumed comparable amounts on the conditioning trials $[F(1,11)=3.67, p>.05]$. The subjects in the short condition consumed means $( \pm S E M) 1.9 \mathrm{ml}$ $( \pm 0.4)$ and $1.5 \mathrm{ml}( \pm 0.3)$, respectively, on the first and second conditioning trials, whereas the subjects in the long condition consumed $3.2 \mathrm{ml}( \pm 0.6)$ and $1.1 \mathrm{ml}( \pm 0.1)$ on these trials. Although there was a small numerical difference between conditions on the first conditioning trial, there was little difference on the second trial. As was expected, the subjects drank less on the second conditioning trial $[F(1,11)=25.29, p<.0005]$, but this decrease did not interact with the duration of the session $[F(1,11)=$ $2.81, p>.10]$.

The test data from the short and long conditions are shown in Figure 1. The counterbalancing of the two flavors and the two chamber types did not affect the test data, nor did it interact with treatment $\left[F_{\mathrm{S}}(1,10)<1.06, p \mathrm{~s}>\right.$ $.30]$, so these factors were collapsed for subsequent analyses. It is clear from an examination of the figure that the short condition showed a stronger CR on the later test trials than did the long condition. This result was confirmed by a within-subjects ANOVA conducted on the test data, which revealed a difference between the long and the short conditions $[F(1,11)=11.57, p<.01]$, a main effect of days $[F(5,55)=12.45, p<.0001]$, and an interaction of these factors $[F(5,55)=4.75, p<.002]$.

This finding would not be anticipated on the basis of predictions from most theories of conditioning that address the role of context exposure on conditioning (Gibbon \& Balsam, 1981; Jenkins et al., 1981; Miller \& Schachtman, 1985a). Earlier studies have shown that longer session durations promoted stronger conditioned responding.

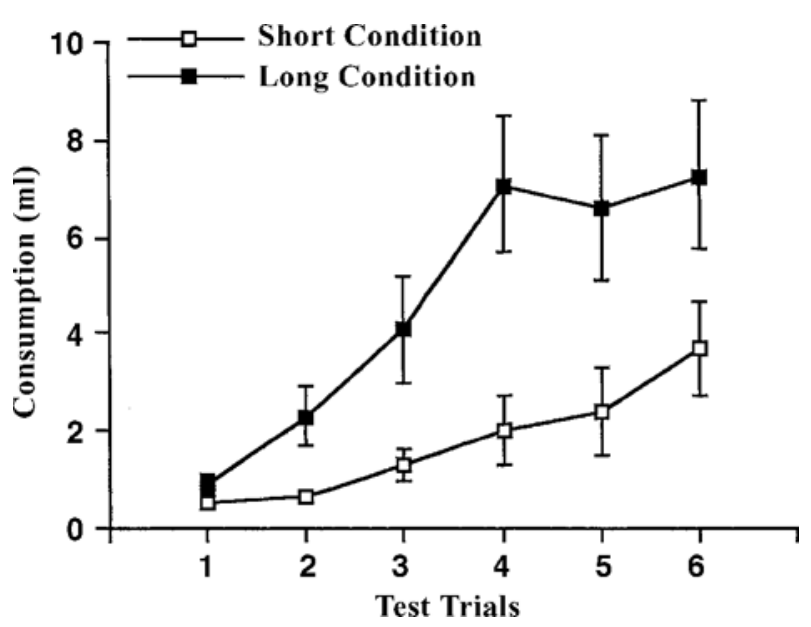

Figure 1. Mean intake ( $\pm S E M s)$ during test trials in the subjects' home cages in Experiment 1. Session duration for the short condition was 15 min during conditioning, whereas that for the long condition was $60 \mathrm{~min}$ during conditioning.
These studies (see Gibbon \& Balsam, 1981; Jenkins et al., 1981; Miller \& Schachtman, 1985a) showed that the CR to a CS was large if the association between the conditioning context and the US was weak and that the CR to the CS was small if this context-US association was strong. Longer session durations are expected to result in weaker context-US associations and to enhance the CR. These earlier views of the effect of context exposure on conditioning stemmed from data for pigeons in an autoshaping procedure (Gibbon \& Balsam, 1981; Jenkins et al., 1981) and for rats in a conditioned suppression procedure (Jenkins \& Shattuck, 1981; Kasprow et al., 1987). Shorter session durations during conditioning enhanced the CR to the $\mathrm{CS}$ in the present experiment. It is not clear what mechanism produced the reduced CR magnitude following longer sessions. It should be noted that the subjects in the long condition that received the CS-US pairings at the beginning of the 60-min session showed a slight numerical tendency toward a weaker CR than did those receiving the pairings at the end of the session. On Test Trials 4-6, the subjects in the long-begin condition that received their pairings early in the session produced means $( \pm S E M)$ of $10.5 \mathrm{ml}( \pm 1.3), 10.7 \mathrm{ml}( \pm 0.7)$, and $9.6 \mathrm{ml}( \pm 2.3)$ on these trials, whereas the long-end condition produced means of $5.7 \mathrm{ml}( \pm 1.8), 5.9 \mathrm{ml}( \pm 2.2)$, and $6.5 \mathrm{ml}( \pm 2.1)$ on these trials. Comparison of these scores on Trial 4 yielded a marginally significant difference $[F(1,10)=$ $3.81, p<.08$ ]. However, both long conditions showed a poorer aversion than did the short condition.

In sum, conditioning was poor when long conditioning sessions occurred, and this effect appeared to be somewhat greater for the conditions in which the CS-US pairings were received at the beginning of the sessions. In Experiment 2, we sought to further examine the role of context and context duration on conditioned taste aversions.

\section{EXPERIMENT 2}

The results of Experiment 1 showed that subjects given CS-US pairings during a short duration session exhibited a stronger $\mathrm{CR}$ to the $\mathrm{CS}$ than did rats given pairings during long sessions. In Experiment 2, we sought to confirm this effect, using longer session durations. The rats in the short condition received a 30 -min conditioning session, whereas the rats in the longer condition received a $180-\mathrm{min}$ session. The short session was lengthened from the $15 \mathrm{~min}$ used in Experiment 1 to $30 \mathrm{~min}$, in order to help reduce any effects of handling cues that occurred shortly before (or after) the flavors were administered in this condition.

As in Experiment 1, all the rats received two CSs. One $\mathrm{CS}$ was paired with $\mathrm{LiCl}$ during a 180-min session, whereas the other CS was paired with $\mathrm{LiCl}$ during a 30-min session. For the long sessions, half of the subjects received their pairings at the beginning of these sessions, whereas the other rats received their pairings at the end of these sessions.

\footnotetext{
Method

Subjects. Nine female and 7 male Sprague-Dawley-derived rats bred in the University of Missouri colony served as subjects. At the
} 
start of the study, the rats ranged in body weight from 266 to $329 \mathrm{~g}$ for females and from 414 to $546 \mathrm{~g}$ for males.

Apparatus, solutions, and drugs. The apparatus was identical to that used in Experiment 1, as were the solutions and the $\mathrm{LiCl}$ dose.

Procedure. The procedure was much like that in Experiment 1, except that the rats did not receive preexposure to the context in this experiment and the sessions were longer. Also, three, rather than two, conditioning trials were given for each flavor, in order to further increase discriminability of the different treatments in the context, as well as the features of the contextual cues themselves.

During the conditioning phase (Days 1-12), all the rats received three conditioning trials with one flavor (Vin or Coff) during a 180min session and three conditioning trials with a second flavor (Vin or Coff) during a 30-min session. One CS was conditioned on Days 1,3 , and 9, and the other CS was conditioned on Days 5, 7, and 11 . For the short session (Condition Short), the rats were placed in the context and remained there for $12.5 \mathrm{~min}$; they then received the flavor for $5 \mathrm{~min}$ and were injected with $\mathrm{LiCl}$. They remained in the context for what remained of the 30-min session (approximately $12.5 \mathrm{~min}$ ) before they were taken to the home cages. For the long session, half of the rats ( $n=8$, counterbalanced for sex), those in the long-begin condition, were placed in the context, remained there for $12.5 \mathrm{~min}$, and then received their 5-min access to flavor, followed by $\mathrm{LiCl}$; they then remained in the context for the rest of the 180-min session (about $162.5 \mathrm{~min}$ ). The rats in the long-end condition were placed in the context and remained there for $162.5 \mathrm{~min}$; they then received their 5-min access to the flavor, followed by the $\mathrm{LiCl}$ injection. They then stayed in the context for the remaining $12.5 \mathrm{~min}$ of the session and were taken to the home cages. No treatments occurred on Days 2, 4, 6, 8, 10, and 12, to allow the rats to recover from the $\mathrm{LiCl}$ injections.

Testing for consumption of the target flavors occurred in the home cages on Days 13-24. There were six 5-min test trials with each CS The two CSs were alternated across the 12 test sessions. On Days 25 and 26 , the rats were tested on water consumption in each context, using the same procedure as that on Days 13-24, except that the drinking tubes were filled with water. This test was used as a potential assessment of the aversion to the contextual cues. If the difference in session duration on conditioned responding was due to differences in associative strength of the contextual cues, differential aversion to the contextual cues might cause a difference in water consumption. That is, an aversion to the contextual cues might elicit a conditioned suppression of water consumption. All unspecified details of the experiment were identical to those of Experiment 1.

\section{Results and Discussion}

There was no significant difference in consumption in the two chamber types during conditioning, although there was a tendency for the rats to drink more in the smaller chambers (Context 1$)$ than in the larger chambers [Context $2 ; F(1,14)=5.11, p>.05]$. Moreover, the rats did consume the vinegar flavor more than the coffee flavor during conditioning $[F(1,14)=12.29, p<.005]$. The subjects in the short condition consumed (mean \pm SEM) $2.6 \mathrm{ml}$ $( \pm 0.5), 2.6 \mathrm{ml}( \pm 0.5)$, and $1.4 \mathrm{ml}( \pm 0.4)$ on the three conditioning trials, respectively, whereas the subjects in the long condition consumed $2.4 \mathrm{ml}( \pm 0.5), 2.4 \mathrm{ml}( \pm 0.6)$, and $1.8 \mathrm{ml}( \pm 0.6)$ on these three trials. A within-subjects ANOVA was conducted on the conditioning data, and this revealed that the subjects in the short and the long conditions drank similar amounts during conditioning $(F<1)$ and that there was no effect of this factor across the 3 days $(F<1)$. The rats consumed less flavor across the three conditioning trials $[F(2,30)=4.54, p<.02]$.
The test data from the short condition and the two long conditions are shown in Figure 2. Neither the counterbalancing of the two flavors nor that of the two chamber types produced a main effect $(F \mathrm{~s}<1)$ or an interaction with treatment for the test data $(F \mathrm{~s}<1.16, p \mathrm{~s}>.30)$, so these factors were collapsed for subsequent analyses. An ANOVA conducted on these data obtained no effect of session duration and no interaction of session duration with test day $(F \mathrm{~s}<1.66, p \mathrm{~s}>.15)$. The difference in session lengths between the short and the long conditions in the present experiment was not sufficient to influence the CR.

A between-groups ANOVA was conducted on the data from the long-begin and long-end conditions. This ANOVA obtained a difference between these conditions, as revealed by a main effect of time of conditioning $[F(1,14)=51.95]$ and days $[F(5,70)=12.28]$ and an interaction of these factors $[F(5,90)=5.90$, all $p \mathrm{~s}<.0002]$. The subjects in the long-begin condition exhibited a much weaker aversion than did those in the long-end condition.

When a within-subjects ANOVA was conducted on the test scores for those rats that received their conditioning trials at the beginning of a long session, a main effect of session duration (long vs. short) was obtained $[F(1,7)=$ $14.38, p<.01]$. The short condition produced a stronger $\mathrm{CR}$ than did the long condition when the conditioning trials occurred at the beginning of this long session. When a similar within-subjects ANOVA was conducted on the scores from the subjects that received their conditioning trials at the end of the long session, the analysis also revealed an effect of session duration $[F(1,7)=14.17, p<$ $.01]$. The short condition for these rats produced a poorer

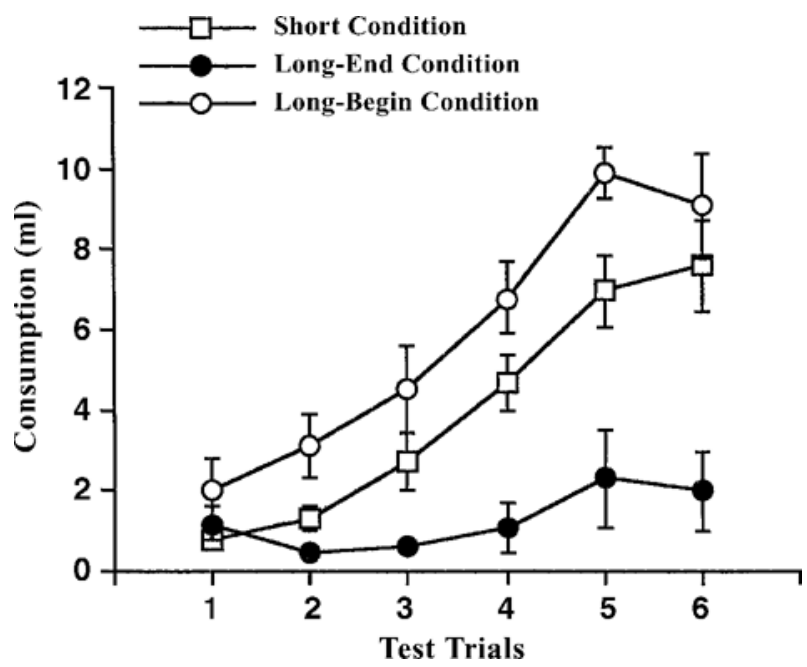

Figure 2. Mean intake ( $\pm S E M$ s) of a saccharin solution on the test trials in the subjects' home cages in Experiment 2. The subjects in the short condition received a 30 -min session duration during conditioning. The subjects in the long-end condition received their CS-US pairings at the end of 180 -min session durations, whereas the subjects in the long-begin condition received their conditioning trials at the beginning of 180 -min session durations. 
CR than did the long (end) condition. When the data from all the subjects are considered, the CR for the short condition was midway between those for the long-end and the long-begin conditions.

On Days 25 and 26, the rats consumed $10.2 \mathrm{ml}( \pm 0.9)$ of water in the short-condition context and $8.7 \mathrm{ml}( \pm 0.7)$ of water in the context in which the long-condition treatment occurred. There was no statistically significant difference in these scores $[F(1,15)=2.21, p>.15]$. A comparison of the long-end $(8.5 \pm 0.8 \mathrm{ml})$ conditions and the long-begin $(8.9 \pm 1.3 \mathrm{ml})$ conditions revealed no significant difference in water consumption for these conditions $(F<1)$.

These results from testing on the flavored solutions show that a strong CR occurs if the CS-US pairings occur at the end of a long session. When the results of Experiments 1 and 2 are considered together, it can be concluded that long sessions produced a poorer CR if the CS-US pairings occurred at the beginning of the sessions. The manner by which context exposure reduces the CR following long conditioning sessions in which the pairings occur at the end of the sessions is not apparent. In Experiment 3 , we explored this issue.

\section{EXPERIMENT 3}

Experiments 1 and 2 showed that long sessions produce a poorer CR than do short sessions if the CS-US pairings occur at the beginning of the sessions. It is not clear, on the basis of the results of those experiments, why greater context exposure (late in the sessions) during conditioning sessions reduces the CR to the CS. One possibility is that context-US associations formed during short sessions or during long-end sessions support the CR to the CS at test. For instance, such sesssions may promote context-mediated second-order conditioning of the CS (Marlin, 1982). That is, contextual cues could serve as a first-order conditioned excitor and support second-order conditioning to the flavor via context-flavor associations. This notion suggests that the CR is strong in the short-session conditions (and the long-end sessions) due to second-order conditioning; extended context exposure following CS-US pairings for long-begin sessions potentially reduces such an effect by extinction of the contextual cues.

Another possibility is that context conditioning is poor with shorter session durations, thereby promoting a strong $\mathrm{CR}$ through the comparator processes described earlier. A strong CR produced by a weaker context-US association would be expected on the basis of comparator processes. Is there reason to expect that shorter sessions might produce poorer context-US associations? Fanselow (1990) and Kiernan and Westbrook (1993) have found that unsignaled footshocks administered immediately after placement of the rat in the context produce poorer context conditioning. Hence, a longer session (more time in the context prior to footshock exposure) produced better context conditioning. Mustaca, Gabelli, Papini, and Balsam (1991) varied the interreinforcement interval (IRI) when un- signaled shocks were given and found that long IRIs produced greater context conditioning when an aversive US was employed. Moreover, there is reason to expect that CS-US pairings occurring early in a lengthy session (Condition Long-Begin) might allow strong context-illness associations to be formed, since the subjects reside in the context for an extended period after the presumed initiation of illness. It was this type of treatment that produced the poorest $\mathrm{CR}$ in Experiment 2.

If the stronger CR for shorter session durations is produced by context-mediated second-order conditioning, extinction of the context following CS training but prior to testing might be expected to reduce the CR to the flavor. Extinction of the contextual cues would extinguish the first-order association that mediated the CR to the CS (Hittsdorf \& Richards, 1982; Rashotte, Griffin, \& Sisk, 1977; Rescorla, 1979; but see Holland \& Rescorla, 1975; Rizley \& Rescorla, 1972). However, if longer sessions produce a poor CR (for the long-begin condition) to the CS because of comparator processes - that is, strong contextUS associationsreducing the magnitude of the CR (Kasprow et al., 1987) - extinction of the contextual cues after CS training should enhance the CR to the CS. It has been established that context-US associations are formed during CTA conditioning (Loy, Alvarez, Rey, \& Lopez, 1993) and that extinction of the contextual cues can influence conditioned responding to the CS by way of such associations (Best, Dunn, Batson, Meachum, \& Nash, 1985).

The procedure in Experiment 3 was much like that in Experiment 1, except that a between-groups design for the session duration factor was employed. In the experiment, we sought to examine the source of the stronger CR that occurs with short sessions, relative to long sessions, when the CS-US pairings occur at the beginning of the session. For some subjects, the context was given extinction exposures after conditioning and prior to testing. If the poor $\mathrm{CR}$ observed for the condition with the longer session duration (when CS-US pairings occurred early in the session) in Experiment 1 was due to greater context conditioning occurring for that treatment, as comparator theories would predict, extinction of the context should increase the CR. If the strong CR for short-duration conditions is due to context-mediated second-order conditioning, context extinction should decrease the CR to the flavor.

\footnotetext{
Method

Subjects. Twenty-three male Sprague-Dawley-derived rats bred in the University of Missouri colony served as subjects. At the start of the study, the rats ranged in body weight from 412 to $563 \mathrm{~g}$.

Apparatus, solutions, and drugs. The apparatus was identical to that used in Experiment 1. The solution (Vin) and $\mathrm{LiCl}$ dose were the same as those in the previous experiments.

Procedure. As has been mentioned, the conditioning procedure was much like that in Experiment 1, although a between-groups design was used for the session duration factor. The rats received a 20min exposure to each context on Day 1, as in Experiment 1. Conditioning occurred on Days 2 and 4 during Phase 1 of the experiment. The rats received a CS-US pairing with Vin in a distinctive context. Each subject was given two conditioning trials with the flavor. Half of the rats were conditioned during 15-min sessions, as was done in
} 


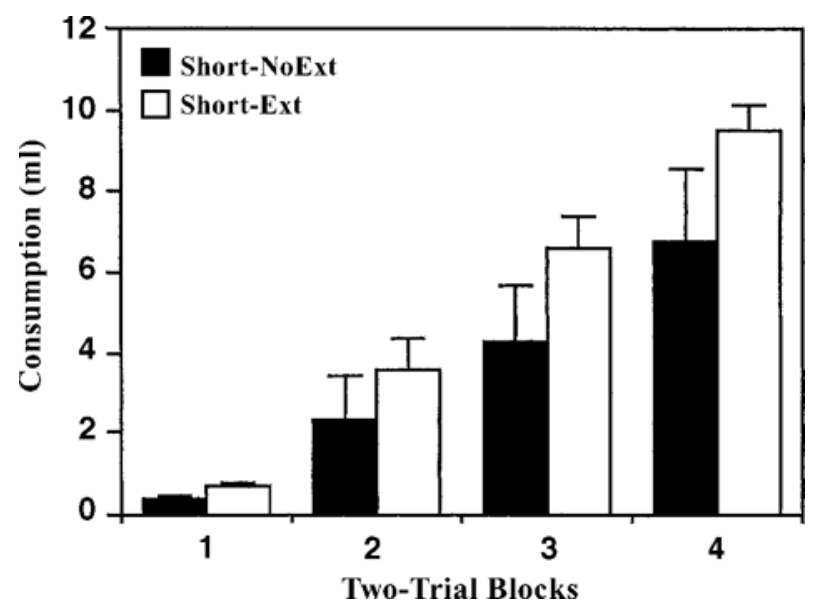

Figure 3. Mean intake $( \pm S E M$ s) during the test trials in Experiment 3. Group Short-NoExt received 15-min sessions during conditioning. Group Short-Ext received 15-min sessions during conditioning and then received extensive extinction to the contextual cues prior to the test on the flavor in the home cages.

Experiment 1. The other rats received their CS-US pairing during 60-min sessions, as occurred for Group Long-Begin in Experiment 1. That is, for these subjects, each CS-US pairing was initiated 5 min into the session, and the animals remained in the context for 50 min after the $\mathrm{LiCl}$ injection. The rats received no treatments on Days 3 and 5 .

Phase 2 occurred on Days 6-13. For the rats experiencing a long session during conditioning, half (Group Long-Ext, $n=6$ ) were placed in their conditioning context and remained there for $90 \mathrm{~min}$ without any drinking tubes present. The remaining subjects that had received a long session during conditioning (Group Long-NoExt, $n=5$ ) remained in the home cages on these days. For the rats that experienced 15-min sessions during conditioning, half (Group Short-Ext, $n=6$ ) were given extinction to the conditioning context during Phase 2, identical to the treatment given to Group Long-Ext. The remaining rats $(n=6)$ in the short-conditioning group (Group Short-NoExt) remained in the home cages during Phase 2. The subjects in Groups Long-Ext and Long-NoExt and those in Groups Short-Ext and Short-NoExt were counterbalanced for consumption of Vin during the conditioning trials.

Testing occurred on Days 14-21. Testing occurred in the home cages with 5-min exposures to vinegar as the test CS. As in Experiment 1 , all the rats received $10 \mathrm{~min}$ of water in the home cages after each day's experimental treatments.

\section{Results and Discussion}

One subject from Group Long-NoExt was eliminated from the experiment due to a procedural error. During the two conditioning trials, the subjects in Groups Short-Ext consumed (mean $\pm S E M) 2.2 \mathrm{ml}( \pm 0.5)$ and $1.2 \mathrm{ml}( \pm 0.5)$, respectively. Group Short-NoExt consumed $2.1 \mathrm{ml}( \pm 0.5)$ and $0.7 \mathrm{ml}( \pm 0.1)$, respectively, on these trials. Group Long-Ext drank $3.4 \mathrm{ml}( \pm 0.6)$ and $0.9 \mathrm{ml}( \pm 0.1)$ on the conditioning trials, whereas Group Long-NoExt consumed $3.6 \mathrm{ml}( \pm 0.9)$ and $0.5 \mathrm{ml}( \pm 0.05)$ on these trials. A $2 \times 2 \times 2$ ANOVA (Ext vs. NoExt $\times$ long vs. short $\times$ days) conducted on the conditioning data obtained an interaction of session duration and trials $[F(1,18)=7.28$, $p<.015]$, since the conditions differed on the first trial, but not on the second. There were no differences between extinction and no-extinction conditions $(F<1)$ and no interactions of the between-groups factors $\left(F_{\mathrm{S}}<1\right)$. There were no differences in consumption on the second conditioning day.

The test data are shown in Figures 3 and 4. A $2 \times 2 \times$ 8 ANOVA (Ext vs. NoExt $\times$ long vs. short $\times$ days) obtained a three-way interaction of the factors $[F(7,144)=$ $2.05, p<.05]$. The difference between Groups ShortNoExt and Long-NoExt emerged on the later test trials. An ANOVA conducted on Test Trials 7-8 produced a marginally significant difference between the NoExt conditions $[F(1,8)=4.93, p=.057]$, confirming the difference observed in Experiment 1, although the effect was smaller in the present experiment, which used a betweengroups design.

There was an effect of context extinction for the shortsession conditions when Groups Short-Ext and Short-NoExt were compared on the test trial performance $[F(1,10)=$ $5.54, p<.05]$. Extinction of the contextual cues reduced the CR for the Short-Ext condition. There was no effect of context extinction for the long-session groups $(p>.10)$. The results from Experiment 3 indicate that the strong CR observed for subjects trained with a short session was due to strong context-US association's enhancing the CR to the CS. Extinction of these cues can reduce the CR to the flavor CS.

\section{EXPERIMENT 4}

The results from Experiment 3 suggest that the context extinction manipulation changed the associative value of the contextual cues for rats given a short conditioning session. Experiment 4 was performed to examine whether this context extinction manipulation could be shown to produce more direct evidence that the context-US associ-

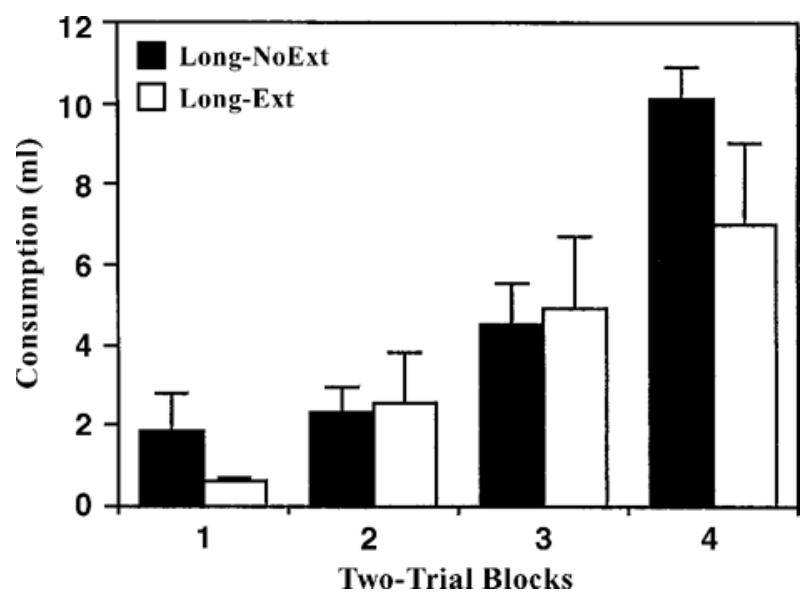

Figure 4. Mean intake ( $\pm S E M$ s) during the test trials in Experiment 3. Group Long-NoExt received 60-min sessions during conditioning. Group Long-Ext received 60-min sessions during conditioning and then received extensive extinction to the contextual cues prior to the test on the flavor in the home cages. 
ation can be changed in value. The final water test used in Experiment 2 sought to examine differences in long and short conditions on conditioned suppression of drinking and obtained no effect. In Experiment 4, we examined the effects of context extinction on the associative strength of contextual cues by examining whether this potential difference in context strength would influence consumption to a novel flavor presented after the subjects received (or did not receive) context extinction. That is, the subjects were given training with 15 -min conditioning sessions with Vin, similar to the short conditions in the previous experiments, and then half of the subjects were given context extinction and half were not given context extinction. Finally, the subjects were tested with a coffee solution in the conditioning context, to examine whether fear of the context in the nonextinguished subjects would influence neophobia (produce a low degree of consumption) of the novel coffee flavor.

We intentionally used a vinegar and coffee solution for the two phases of the experiment because our laboratory has frequently used these solutions as experimental and control solutions without substantial generalization between them (Calton, Mitchell, \& Schachtman, 1996, Experiments 2 and 4; Schachtman, Gustavson, Chelonis, \& Bourne, 1992).

\section{Method}

Subjects. Ten male Sprague-Dawley rats served as subjects. The body weights ranged from 224 to $270 \mathrm{~g}$. The rats were water deprived prior to the start of the experiment, using a graded water deprivation schedule as in the previous experiments, but the schedule culminated in 15 min of water access each day. Fifteen minutes of water access occurred in the home cages after each day's treatments

Apparatus, solutions, and drugs. The apparatus was the same as that in the previous experiments, and the context was identical to Context 2 in Experiment 1. The solution (Vin) and $\mathrm{LiCl}$ dose were the same as that in the previous experiments. A $1 \%(\mathrm{w} / \mathrm{v})$ coffee solution (Sanka) was also used in the experiment.

Procedure. The subjects were placed in the context on Day 1 for $20 \mathrm{~min}$, with water available in the drinking tubes to acclimate the rats to drinking in these chambers. On Day 2, all the subjects received a 15-min session. After residing in the context for $5 \mathrm{~min}$, the rats were given a 5-min presentation of vinegar (Vin), followed immediately by an i.p. injection of $0.15 \mathrm{M} \mathrm{LiCl}$ at $0.5 \%$ body weight. The rats then remained in the context for $5 \mathrm{~min}$ before being removed and taken to the home cages. Day 4 was identical to Day 2. The rats remained in the home cages on Days 3 and 5, to recover from the injections. On Days 6-13,5 subjects received extinction of contextual cues (Group Context-Ext), whereas the other 5 rats (Group No Context-Ext) received no context extinction (i.e., they remained in the home cages). On each of these 8 days, the rats in Group Context-Ext were placed in the context for 90 min without any drinking tubes.

On Day 14, all the subjects were placed in the context for $15 \mathrm{~min}$. Five minutes after being placed in the context, they received a 5-min presentation of a $1 \%$ coffee solution (Coff).

\section{Results and Discussion}

Group No Context-Extconsumed (mean \pm SEM) $1.8 \mathrm{ml}$ $( \pm 0.3)$ and $0.8 \mathrm{ml}( \pm 0.2)$ on the first and second conditioning trials, respectively, whereas Group Context-Ext consumed $1.6 \mathrm{ml}( \pm 0.3)$ and $1.0 \mathrm{ml}( \pm 0.3)$ on these tri- als. A $2 \times 2$ (group $\times$ days) ANOVA was conducted on the consumption scores from the vinegar conditioning trial on Days 2 and 4. No main effect for group occurred $[F(1,8)<1]$, nor did an interaction of group and days occur $[F(1,8)<1]$. The main effect for days was significant $[F(1,8)=11.32, p<.01]$, with intake decreasing from the first to the second conditioning trials.

Group No Context-Ext consumed $0.8 \mathrm{ml}( \pm 0.5)$ on the test trial, whereas Group Context-Ext consumed $2.6 \mathrm{ml}$ $( \pm 0.6)$. An ANOVA was conducted on the scores from the Day 14 coffee exposure trial. This analysis yielded a marginally significant main effect of group $[F(1,8)=5.29$, $p=.0504]$. Group No Context-Ext consumed less coffee on the Day 14 test trial than did Group Context-Ext. The context extinction treatment given to the latter group appears to have reduced the value of the context and to have allowed less of a neophobic reaction to the novel coffee solution. As was mentioned, we used a vinegar and coffee solution for the two phases of the experiment because our laboratory has frequently used these solutions as experimental and control solutions without substantial generalization between them (Calton et al., 1996, Experiments 2 and 4; Schachtman et al., 1992). However, it is possible that the subjects in the present experiment generalized these two flavors in such a way that they responded to the coffee solution as though it were Vin, so that the present results simply reflect the pattern of consumption that occurred for the short conditions in Experiment 3 (i.e., context extinction increases consumption). That is, the group given context extinction produced a reduced aversion to Vin, relative to the nonextinguished condition, and so the possibility of stimulus generalization cannot be ruled out as an explanation of the increased consumption of coffee. There are also few, if any, previously published demonstrations in which context aversions produced by internal malaise elicited elevated neophobic responses and extinction of the context reduced this effect, and so the mechanism producing the present effect remains unclear. However, the findings are consistent with a weaker context$\mathrm{LiCl}$ association in subjects given context extinction.

\section{GENERAL DISCUSSION}

In these experiments, a CTA procedure was used to assess the effects of varying session duration and, hence, the extent of exposure to the contextual cues, during conditioning. Conditioning involved two or more pairings of a flavor and an illness that occurred in distinctive contexts outside of the home cages. Testing for the CR to the flavored CS occurred in the home cages. The experiments showed that a shorter session duration produced a stronger CTA than did a longer session duration. Specifically, longer sessions produced a weak CTA if the CS-US pairings occurred at the beginning of long sessions.

The results of Experiment 3 suggest that contextmediated second-order conditioning contributed to the large CR produced by the short conditions. That is, context-US associations were acquired during conditioning, they 
served as first-order conditioned excitors, and they supported second-order conditioning to the flavor via contextflavor associations. This possibility suggests that the CR was strong in the short session conditions due to secondorder conditioning and that one can reduce such an effect by extinction of these contextual cues. In Experiment 3, context extinction after conditioning with a short session reduced the CR to the CS, thereby showing that the contextual cues were supporting the strong CR to the CS in this condition.

In Experiment 4, the subjects were given CS-US pairings with a short session duration $(15 \mathrm{~min})$. The subjects that did not receive postconditioning context extinction displayed a marked decrease in flavor consumption to the novel flavor, coffee, in the presence of these contextual cues. The subjects apparently formed an association between the contextual cues and illness during conditioning in the short sessions, and this association increased neophobia to a novel flavor unless these contextual cues were extinguished prior to the neophobia test. It is possible, however, that the rats generalized the conditioning flavor and the test flavor, so that the present results simply reflect the pattern of results that occurred for the short conditions in Experiment 3. That is, the group given context extinction produced a reduced aversion to Vin, relative to the nonextinguished condition, and this possibility cannot be ruled out as an explanation of the neophobia effect in Experiment 4.

Second-order conditioning as a mechanism underlying the strong CR in the short-session conditions cannot readily explain some of the present findings. First, a secondorder conditioning account does not readily address why a relatively poor CR in the long-begin conditions occurred, relative to that in the long-end conditions. According to a second-order conditioning view, this poor CR indicates that context-US associations were weaker for the longbegin conditions, since a poor CR suggests weak contextmediated second-order conditioning. It is unclear how session time prior to CS-US pairings preserves this potential second-order conditioning, whereas session time after the pairing does not. It is possible that context extinction following CS-US pairings (long-begin conditions) is much greater than context extinction that occurs prior to the CS-US pairings (long-end conditions). It is also possible that the greater exposure to the contextual cues prior to CS-US pairings for the long-end conditions reduced the salience of the context and, thereby, decreased its ability to compete with the CS for associative strength.

Second, given a second-order conditioning account of the short-session-long-session difference in the present experiments, it is not clear why the long-end condition showed a stronger CR than did the short condition in Experiment 2. In Experiment 2, Group Long-End showed a greater CR than did the subjects in the short condition. Group Long-End yielded means of $1.2 \mathrm{ml}( \pm 0.4), 0.5 \mathrm{ml}$ $( \pm 0.1), 0.6 \mathrm{ml}( \pm 0.1)$, and $1.1 \mathrm{ml}( \pm 0.6)$ on the first four test trials, whereas Condition Short (all the subjects) yielded means of $0.8 \mathrm{ml}( \pm 0.1), 1.3 \mathrm{ml}( \pm 0.3), 2.7 \mathrm{ml}( \pm 0.7)$, and $4.7 \mathrm{ml}( \pm 0.7)$. There is no reason why second-order con- ditioning (assuming that this is the only process that supports a relatively greater $\mathrm{CR}$ ) should be greater for the long-end treatment, relative to the short condition.

Although context-mediated second-order conditioning appears to exert an influence on context duration effects in certain cases (such as the short session duration employed in Experiments 1, 3, and 4), it might be most reasonable to conclude that the role of session duration in CTA learning involves several roles for contextual cues in conditioned performance and that these roles may differ depending on the length of the session.

\section{REFERENCES}

Balsam, P. D., \& Schwartz, A. L. (1981). Rapid contextual conditioning in autoshaping. Journal of Experimental Psychology: Animal Behavior Processes, 7, 382-393.

Balsam, P. D., \& Tomie, A. (1985). Context and learning. Hillsdale, NJ: Erlbaum.

BEST, M. R. (1982). Nonassociative and associative sources of interference with the acquisition of a flavor aversion. In M. L. Commons, R. J. Herrnstein, \& A. R. Wagner (Eds.), Quantitative analyses of behavior: Vol. 3. Acquisition (pp. 67-85). Hillsdale, NJ: Erlbaum.

Best, M. R., Dunn, D. P., Batson, J. D., Meachum, C. L., \& Nash, S. M. (1985). Extinguishing conditioned inhibition in flavour-aversion learning: Effects of repeated testing and extinction of the excitatory element. Quarterly Journal of Experimental Psychology, 37B, 359-378.

Bouton, M. E., \& Bolles, R. C. (1985). Contexts, event-memories, and extinction. In P. D. Balsam \& A. Tomie (Eds.), Context and learning (pp. 133-166). Hillsdale, NJ: Erlbaum.

Calton, J. L., Mitchell, K. G., \& Schachtman, T. R. (1996). Conditioned inhibition produced by extinction of a conditioned stimulus. Learning \& Motivation, 27, 335-361.

Chelonis, J. J., Calton, J. L., Hart, J. A., \& Schachtman, T. R. (1999). Attenuation of the renewal effect by extinction in multiple contexts. Learning \& Motivation, 30, 1-14.

Domuan, M. (1980). Effects of intertrial interval on taste-aversion learning in rats. Physiology \& Behavior, 25, 117-125.

DomJAn, M. (1983). Biological constraints on instrumental and classical conditioning: Implications for general process theory. In G. H. Bower (Ed.), The psychology of learning and motivation (Vol. 17, pp. 215277). San Diego: Academic Press.

FANSELOW, M. S. (1990). Factors governing one-trial contextual conditioning. Animal Learning \& Behavior, 18, 264-270.

GibBon, J., \& BALSAM, P. D. (1981). Speading associations in time. In C. M. Locurto, H. S. Terrace, \& J. Gibbon (Eds.), Autoshaping and conditioning theory (pp. 219-253). New York: Academic Press.

GoRdON, W. C., \& MOWRER, R. R. (1980). An extinction trial as a reminder treatment following electroconvulsive shock. Animal Learning \& Behavior, 8, 363-367.

HitTSDORF, M., \& RichaRdS, R. W. (1982). Aversive second-order conditioning in the pigeon: Elimination of conditioning to CS1 and effects on established second-order conditioning. Canadian Journal of Psychology, 36, 462-477.

Holland, P. C., \& Rescorla, R. A. (1975). The effect of two ways of devaluing the unconditioned stimulus after first- and second-order conditioning. Journal of Experimental Psychology: Animal Behavior Processes, 1, 355-363.

Jenkins, H. M., Barnes, R. A. \& Barrera, F. J. (1981). Why autoshaping depends on trial spacing. In C. M. Locurto, H. S. Terrace, \& J. Gibbon (Eds.), Autoshapingand conditioning theory (pp. 255-284). New York: Academic Press.

Jenkins, H. M., \& Shattuck, D. (1981). Contingency in fear conditioning: A reexamination. Bulletin of the Psychonomic Society, 17, 159-162.

Kasprow, W. J., Schachtman, T. R., \& Miller, R R. (1987). The comparator hypothesis of conditioned response generation: Manifest conditioned excitation and inhibition as a function of the relative excitatory strength of CS and conditioning context at the time of testing. Journal of Experimental Psychology: Animal Behavior Processes, 13, 395-406. 
Kiernan, M. J., \& Westbrook, R. F. (1993). Effects of exposure to a to-be-shocked environment upon the rat's freezing response: Evidence for facilitation, latent inhibition, and perceptual learning. Quarterly Journal of Experimental Psychology, 46B, 271-288.

Loy, I., Alvarez, R., Rey, V., \& Lopez, M. (1993). Context-US associations rather than occasion setting in taste aversion learning. Learn ing \& Motivation, 24, 55-72.

Marlin, N. A. (1982). Within-compound associations between the context and the conditioned stimulus. Learning \& Motivation, 13, 526-541.

Miller, R. R., \& Matzel, L. D. (1988). The comparator hypothesis: A response rule for the expression of associations. In G. H. Bower (Ed.), The psychology of learning and motivation (Vol. 22, pp. 51-92). Hillsdale, NJ: Erlbaum.

Miller, R. R, \& Schachtman, T. R. (1985a). Conditioning context as an associative baseline: Implications for response generation and the nature of conditioned inhibition. In R. R. Miller \& N. E. Spear (Eds.), Information processing in animals: Conditionedinhibition (pp. 51-88) Hillsdale, NJ: Erlbaum.

Miller, R. R., \& Schachtman, T. R. (1985b). The several roles of context at the time of retrieval. In P. D. Balsam \& A. Tomie (Eds.), Context and learning (pp. 167-194). Hillsdale, NJ: Erlbaum.

Mustaca, A. E., Gabelli, F., Papini, M. R., \& Balsam, P. (1991). The effects of varying the interreinforcement interval on appetitive contextual conditioning. Animal Learning \& Behavior, 19, 125-138.

Rashotte, M. E., Griffin, R. W., \& Sisk, C. L. (1977). Second-order conditioning of the pigeon's keypeck. Animal Learning \& Behavior, 5, 25-38.

Rescorla, R. A. (1979). Aspects of the reinforcer learned in secondorder Pavlovian conditioning. Journal of Experimental Psychology: Animal Behavior Processes, 5, 79-95.

Rescorla, R. A, Durlach,P. J., \& Grau, J. W. (1985). Contextual learning in Pavlovian conditioning. In P. D. Balsam \& A. Tomie (Eds.), Context and learning (pp. 23-56). Hillsdale, NJ: Erlbaum.

Rizley, R. C., \& Rescorla, R. A. (1972). Associations in second-order conditioning and sensory preconditioning. Journal of Comparative \& Physiological Psychology, 81, 1-11.

Schachtman, T. R., Gustavson, K. K., Chelonis, J. J., \& Bourne, M. J. (1992). Effects of US reinstatement on the potential of an extinguished CS to attenuate manifest learning about another CS. Learning \& Motivation, 23, 250-268.

WeAver, M. S., \& Gordon, W. C. (1988). The role of contextual stimuli in the blocking paradigm. Psychobiology, 16, 59-66.

(Manuscript received January 21, 2003; revision accepted for publication June 23, 2003.) 